\title{
The Association of Antenatal Steroids and Hypoglycemia in Preterm Neonates
}

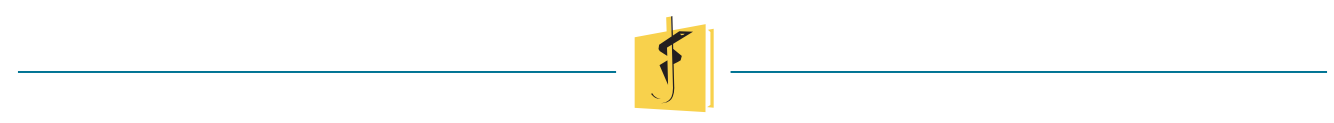

\author{
John Ryan G. Viar, MD; Elaine C. Cunanan, MD
}

\begin{abstract}
Objective Antenatal steroids have shown to decrease the rate of neonatal complications and morbidity; however, neonates are predisposed to significant hypoglycemia resulting in invasive interventions and prolonged nursery admissions. The risk of hypoglycemia in the preterm has been well studied, but the association of antenatal steroids and hypoglycemia in preterm neonates has not been well explored. Thus, we sought to determine the association of antenatal steroids given to mothers who delivered prematurely and the development of neonatal hypoglycemia.
\end{abstract}

Methods A cross-sectional study using chart review was done on mother-preterm neonate pairs admitted in the charity obstetrical ward of The University of Santo Tomas Hospital from January 1, 2018 to December 31, 2019. The subjects were mothers either given or not given antenatal steroids before preterm delivery and their respective neonates. The provision of antenatal steroids was the primary exposure, while neonatal hypoglycemia was the primary outcome. Measurement of association was done using odds ratios. Univariate and multivariate logistic regression analyses were done.

John Ryan Viar

jayrviar@gmail.com

Department of Internal Medicine, Section of

Endocrinology, Diabetes and Metabolism

University of Santo Tomas Hospital, Manila, Philippines
Results Of the 69 preterm neonates included in the study, hypoglycemia was observed in 14 neonates, among which 8 neonates were exposed to antenatal steroids. After examining the association using Fisher's exact formula and controlling for potential confounders, neonatal hypoglycemia was not significantly higher among neonates exposed to antenatal steroids.

Conclusion Antenatal steroids given to mothers who delivered preterm were not associated with the development of neonatal hypoglycemia. A prospective study model, larger population size and longer study coverage should be made to strengthen the outcome of the study.

\section{INTRODUCTION}

In 2005, an estimated $9.6 \%$ of births $(12.9$ million births) in the world were preterm, from which 85\% (11 million births) were found in Africa and Asian countries.[1] Antenatal steroids have shown benefit in pregnancies at risk for preterm delivery, as demonstrated in several studies. The provision of steroids antenatally has shown to decrease the rate of perinatal death, respiratory distress syndrome, necrotizing enterocolitis and neonatal intensive care unit (NICU) admissions.[2] However, antenatal corticosteroid administration has an impact on maternal glucose control. It may result in maternal hyperglycemia via direct promotion of hepatic gluconeogenesis, which leads to fetal pancreatic beta cell hyperplasia or hyperinsulinemia and 
subsequent neonatal hypoglycemia.[2,3] Another proposed mechanism of antenatal steroid resulting in neonatal hypoglycemia is through direct suppression of fetal adrenal glands, as reported by Saulnier and Kurtoglu.[4] Prematurity by itself is already a risk for neonatal hypoglycemia. In a study about neonatal glucose screening among later preterm deliveries, more than $50 \%$ developed hypoglycemia, while $19 \%$ developed severe hypoglycemia.[5]

The hyperglycemia resulting from antenatal steroids is evident on the first three days of administration. Schumacher et al. in their study demonstrated that antenatal betamethasone resulted in an increase in blood sugar levels in the first 24 to 72 hours, with daily blood glucose averaging from 96.7 to $129.6 \mathrm{mg} / \mathrm{dL}$. The study observed impaired glucose tolerance over the first 68 hours after betamethasone administration with more significant effects in patients with diabetes.[2] If preterm delivery had been imminent within the period where antenatal steroids had their deleterious effects, it could result in significant neonatal hypoglycemia and morbidity.

Even in non-steroid-treated pregnancy, hyperglycemia in pregnancy itself results in adverse neonatal outcomes. In a prospective observational study by Voormolen et al., neonatal hypoglycemia was observed among patients with gestational diabetes mellitus (GDM) regardless of hyperglycemia management either by diet alone or with insulin. [6] The International Diabetes Federation (IDF) in 2017 estimated that the overall prevalence of diabetes in the Philippines compared to other countries was $6.2 \%$. Specifically, about 21.3 million or $16.2 \%$ of live births in women had hyperglycemic disorders during pregnancy. These include GDM estimated at $86.4 \%$, overt diabetes mellitus at $6.2 \%$, and other types of diabetes detected first in pregnancy at 7.4\%. The South-East Asian Region, in which The Philippines is included, shares the highest prevalence of hyperglycemia in pregnancy at $24.2 \%$.

Untoward events of uncontrolled hyperglycemia in pregnancy are documented in several studies. Risks include fetal abnormalities, preeclampsia, macrosomia and neonatal hyperbilirubinemia. [7] Consequently, elevated maternal blood glucose during labor and delivery increases the risk of neonatal hypoglycemia and fetal distress, as well as birth asphyxia and abnormal fetal heart rate. [8] There is also an increased risk for developing obesity and type 2 diabetes mellitus in the offspring later in life. [7]

We aimed at determining the association of antenatal steroids given to mothers who delivered preterm and the risk of hypoglycemia in preterm neonates. Supported with the above literature, we hypothesized that the inherent risk of hypoglycemia due to prematurity and the effects of antenatal corticosteroids given to the mother will result in significant neonatal hypoglycemia, necessitating prolonged nursery care and hospitalization. The information gathered in this study will add to the knowledge on mechanisms of neonatal hypoglycemia in prematurity and maternal hyperglycemia. This could emphasize strict monitoring of pregnant patients and anticipation for complications in the neonate.

\section{METHODOLOGY}

\section{Study Design and Methods}

A cross-sectional study using medical chart data was conducted in a tertiary training hospital involving pregnant women who delivered prematurely and either given or not given antenatal steroids. The study included mother-preterm neonate pairs admitted in the obstetrical charity ward of The University of Santo Tomas Hospital from January 1, 2018 to December 31, 2019. The study has been approved by The University of Santo Tomas Hospital Research Ethics Committee (REC).

Demographical and outcome data were obtained from their medical charts. The subjects were mothers either given or not given antenatal steroids before preterm delivery and their respective neonates. The provision of antenatal steroids was the primary exposure, while neonatal hypoglycemia was the primary outcome. Medical records with the following information were included: mothers 19 years old and above; mothers who delivered between 28 to 36 weeks and 6 days age of gestation; mothers who were either given or not given antenatal steroids between 24 to 36 weeks age of gestation, according to the primary physicians' best management decision and timing of inevitable delivery; and live preterm births without congenital malformations. Medical records with the following information were excluded from the study: mothers with uncontrolled obstetrically unrelated diseases other than diabetes; mothers with acute hyperglycemic complications 
like diabetic ketoacidosis or severe hypoglycemia; pregnant women who underwent surgery not related to pregnancy before giving birth; ectopic pregnancy; steroids given antenatally other than dexamethasone and betamethasone; twin or multiple neonates; and neonates assessed to have persistent hypoglycemia due to inherent metabolic or hormonal disorders.

Prior to data collection, permissions were formally requested to the medical records section, as well as to the departments of obstetrics and gynecology and pediatrics in compliance to the Data Privacy Act. Gathering for mother-neonate pairs started with the use of patient admission logbooks. Records of pregnant women were screened for preterm labor and the collected names of candidate motherneonate pairs were then traced and retrieved in the medical records section. For the maternal characteristics, age, parity and the presence of diabetes (overt, gestational, no diabetes) were noted. The administration of antenatal steroids was also recorded. In practice, dexamethasone is given at 6 mg intramuscularly every 12 hours for 4 doses, while betamethasone is given at $12 \mathrm{mg}$ intramuscularly every 24 hours for 2 doses.[9] Only the presence or absence of the said steroids is taken into account and not the number of completed dosages nor the number of doses given per mother. Other maternal characteristics included the provision of isoxsuprine as tocolysis and maternal diseases other than diabetes. The presence of neonatal hypoglycemia, defined as blood glucose level of $\leq 47 \mathrm{mg} / \mathrm{dL}$, was recorded. A bedside point-of-care capillary blood glucose determination was used, as this is the practice in the nursery to determine neonatal blood glucose levels. The first determination of blood glucose via heel-prick method with a value of $\leq 47$ $\mathrm{mg} / \mathrm{dL}$ was used to define neonatal hypoglycemia. Other neonatal characteristics included gender, mode of delivery, birth weight and corresponding adequacy per age and maturity rating.

Data reconciliation was done for incomplete records but justified not to be removed from the study. Some missing data from the mothers' medical records were found and supplemented from the corresponding neonates' medical records and vice versa.

\section{Statistical Analysis}

The statistical analysis was performed using STATA/ IC 15.1 (College Station, Texas). Maternal and neonatal demographic data were reported as means \pm SD and frequency (percentage) whenever appropriate. To determine the relationship between administration of antenatal steroids to the mother and subsequent development of neonatal hypoglycemia, we reported odds ratios. The statistical significance of the unadjusted odds ratio was computed using the Fisher's exact formula. Adjusted odds ratio estimates were computed and tested for statistical significance using a multivariate logistic approach with the model adjusted for the influence of maternal comorbidities, maternal diabetes mellitus status and mode of delivery. Exploration of the relationship of maternal and neonatal factors to hypoglycemia was also computed using univariate logistic regression for each factor.

\section{RESULTS}

At the end of the study, 127 medical records of mothers were screened for preterm labor. Fortythree (43) of these records were excluded because they were medical management-only admissions. Eighty-four (84) records were then gathered with confirmed preterm delivery, from which 73 motherneonate pairs were matched after removing 11 records based on the exclusion criteria. Sixty-nine (69) mother-neonate pairs were finally included for analysis after excluding four records due to neonatal exclusion factors.

Maternal and neonatal characteristics according to the provision of antenatal steroids are shown in Table 1. Twenty-nine (29) mothers were given antenatal steroids. Twenty-one (21) had no diabetes mellitus. Among the 69 neonates included in the study, 14 neonates were observed to have neonatal hypoglycemia based on the bedside blood glucose measurement of $\leq 47 \mathrm{mg} / \mathrm{dL}$ in the first hour of life. Among these neonates, eight neonates were exposed to antenatal steroids. The mean weight of neonates exposed to antenatal steroids was also lighter $(1.89 \pm 0.49 \mathrm{~kg}$ compared to $2.28 \pm 0.45)$. Majority of the neonates included in the study were adequate for gestational age.

Table 2 shows the association of antenatal steroid administration to the development of neonatal hypoglycemia. It showed that mothers given antenatal steroids were 2.16 times more likely to develop neonatal hypoglycemia than mothers who were not given antenatal steroids (unadjusted OR 2.16, 95\% 
Table 1. Maternal and neonatal demographic data of the 69 mother-neonate pairs grouped into those given antenatal steroids and those who were not given antenatal steroids. Data reported as $n(\%)$ or mean \pm SD.

No Antenatal Steroid

$(n=40)$

\section{Maternal Characteristics}

Age (years)

Multiparity

$29 \pm 7$

$21(52)$

$3(8)$

Tocolysis

Maternal Comorbidities

Chronic Hypertension

Infection

Pregnancy-related Hypertension

None reported

Diabetes Mellitus type

No DM

GDM

Overt DM

$\begin{array}{cc}4(10) & 2(7) \\ 2(5) & 4(14) \\ 4(10) & 6(21) \\ 30(75) & 17(59)\end{array}$

29 (72)

$21(72)$

$10(25)$

$6(21)$

1 (2)

\section{Neonatal Characteristics}

Neonatal Hypoglycemia

$\begin{array}{cc}6(15) & 8(28) \\ 26(65) & 16(55) \\ 8(20) & 16(55) \\ 22(55) & 16(55) \\ 2.28 \pm 0.45 & 1.89 \pm 0.49 \\ - & 1(3) \\ 2(5) & 5(17) \\ 24(60) & 21(72) \\ 14(35) & 2(7)\end{array}$

Vaginal Delivery

Given Antenatal Steroid

( $n=29$ )

Early Preterm

Male

Birthweight $(\mathrm{kg})$

ELBW

LBW

$14(35)$

$28 \pm 7$

15 (52)

$12(41)$

NBW

39 (98)

$26(90)$

AGA

$1(2)$

1 (3)

SGA, Symmetrical

2 (7)

$D M$, diabetes mellitus; GDM, gestational diabetes mellitus; $E L B W$, extremely low birth weight; $L B W$, very low birth weight; $L B W$, low birth weight; NBW, normal birth weight; $A G A$, adequate for gestational age; SGA, small for gestational age.

Table 2. Association for Administration of Antenatal Steroid and Neonatal Hypoglycemia

\begin{tabular}{lccc} 
& $\begin{array}{c}\text { Odds } \\
\text { Ratio }\end{array}$ & $95 \%$ Confidence Interval & p-value \\
\hline Unadjusted & 2.16 & $0.64-7.26$ & 0.235 \\
Adjusted* & 2.24 & $0.62-8.07$ & 0.218 \\
\hline
\end{tabular}

*Adjusted for the influence of maternal comorbidities, maternal diabetes mellitus status and mode of delivery.

$\mathrm{Cl}$ 0.64-7.26), even after adjusting for the influence of maternal comorbidities, maternal diabetes status and mode of delivery (adjusted OR 2.24, 95\% Cl 0.62 to 8.07$)$. However, this association failed to reach statistical significance $(p=0.235$ and 0.218 , respectively).

Table 3 explores the association of maternal and neonatal factors to neonatal hypoglycemia. Among 
Table 3. Univariate analysis exploring association of neonatal hypoglycemia to maternal and neonatal factors.

\begin{tabular}{|c|c|c|c|}
\hline & Odds Ratio & 95\% C.I. & p-value \\
\hline \multicolumn{4}{|l|}{ Maternal Characteristics } \\
\hline Age (years) ${ }^{a}$ & 1.01 & $0.93-1.10$ & 0.772 \\
\hline Multiparity & 1.28 & $0.39-4.20$ & 0.677 \\
\hline Tocolysis & 1.60 & $0.42-6.08$ & 0.490 \\
\hline \multicolumn{4}{|l|}{ Maternal health } \\
\hline Chronic hypertension & 2.44 & $0.38-15.66$ & 0.348 \\
\hline Infection & 0.98 & $0.10-9.51$ & 0.983 \\
\hline Pregnancy-related hypertension & 2.09 & $0.44-9.86$ & 0.352 \\
\hline None reported & Reference & & \\
\hline \multicolumn{4}{|l|}{ Diabetes mellitus type } \\
\hline No DM & Reference & & \\
\hline GDM & 3.68 & $1.02-13.38$ & 0.047 \\
\hline Overt DM & 3.07 & $0.24-38.55$ & 0.385 \\
\hline \multicolumn{4}{|l|}{ Neonatal Characteristics } \\
\hline Cesarean Delivery & 1.75 & $0.54-5.71$ & 0.354 \\
\hline Early Preterm & 0.70 & $0.19-2.52$ & 0.586 \\
\hline Male & 0.37 & $0.11-1.25$ & 0.110 \\
\hline Birthweight $(\mathrm{kg})^{\mathrm{b}}$ & 1.01 & $0.84-1.20$ & 0.924 \\
\hline \multicolumn{4}{|l|}{ Birthweight Categories } \\
\hline ELBW & ** & & \\
\hline VLBW & ** & & \\
\hline LBW & 0.86 & $0.23-3.25$ & 0.821 \\
\hline NBW & Reference & & \\
\hline \multicolumn{4}{|l|}{ Adequacy of Weight for Age } \\
\hline Small for Gestational Age & 4.42 & $0.56-34.57$ & 0.157 \\
\hline
\end{tabular}

aAge is centered at 30 years old as such OR is interpreted in terms of every 1 year increase or decrease from age 30 years old; ${ }^{b}$ Birth weight is centered at 3.2 and rescaled to every $0.1 \mathrm{~kg}$ or (100 g) increase or decrease from $3.2 \mathrm{~kg}(3200 \mathrm{~g})$; ** Categories were not included in the analysis due to small size of observation within grouping. DM, diabetes mellitus; GDM, gestational diabetes mellitus; ELBW, extremely low birth weight; VLBW, very low birth weight; $L B W$, low birth weight; NBW, normal birth weight.

these factors, only gestational diabetes mellitus was significantly associated with the development of neonatal hypoglycemia $(p=0.047)$.

\section{DISCUSSION}

Hypoglycemia is considered transient if it occurred and lasted within the first 48 hours of life. Prematurity, infants of diabetic mothers, small and large for gestational age are the known and established risk factors for hypoglycemia in the newborn.[10] Due to the concern for substantial neurodevelopmental morbidity in neonates with hypoglycemia, recommendations made by the American Academy of Pediatrics (AAP) and Pediatric Endocrine Society (PES) provide guidelines in screening and treating suspected hypoglycemic neonates, especially because some may be asymptomatic.[11] The AAP focuses on hyperglycemia in the first 24 hours of neonatal life - also known as transitional hypoglycemia, and offers guidance for screening infants who are at risk. A goal of $45 \mathrm{mg} / \mathrm{dL}$ or greater is recommended prior to feeding. The PES, on the other hand, focuses on the period beyond 48 hours, with a higher blood glucose goal of greater than $50 \mathrm{mg} / \mathrm{dL}$.[11] A working numerical definition of neonatal hypoglycemia of less than $47 \mathrm{mg} / \mathrm{dL}$ was used in our study, as this is still widely used and accepted. 
We examined the relationship between antenatal steroids and development of neonatal hypoglycemia. In our study, antenatal steroids given to mothers were not significantly associated with hypoglycemia among preterm neonates. Based on our results, it was observed that mothers who were given antenatal steroids were two times more likely to develop neonatal hypoglycemia, even after adjusting for confounders.

The corticosteroids used in the study were betamethasone and dexamethasone, which reflects the current practice for antenatal care at risk for preterm delivery. In practice, a single course of antenatal corticosteroids should be given to mothers at risk for preterm delivery between 24 to 34 weeks. It may be given to women at risk between 34 to 36 weeks.[9] Neonates who were not given steroids in this study were from mothers who either: (1) had imminent preterm delivery and had no time for steroid administration; or (2) fall into 34 to 36 weeks age of gestation (AOG), in which steroids are not routinely given.

The association of antenatal steroids to the development of neonatal hypoglycemia was adjusted after considering maternal and neonatal factors, which included maternal comorbidities, maternal diabetes status and mode of delivery. These factors were observed to show the likelihood of developing neonatal hypoglycemia but were also not statistically significant after exploration using the univariate analysis. This could be attributed to small sample size showing neonatal hypoglycemia and it was not comparable to their counterpart showing no neonatal hypoglycemia, thus, resulting in poor precision in the analysis. Nevertheless, it was interesting to discuss such observations: hypertension in pregnancy, either chronic hypertension or pregnancy-related, resulting in maternal stress that in return may result to neonatal hypoglycemia. Gestational diabetes mellitus, on the other hand, was significantly associated with neonatal hypoglycemia. Maternal hyperglycemia was observed to cause neonatal hypoglycemia through mechanisms discussed earlier.[2,3]

It is also interesting to note that a majority of the mothers administered with tocolytics was also given antenatal steroid. Tocolysis has almost always been a part of the management at the start of threatened preterm delivery. It is supplanted with the provision of antenatal steroids in anticipation of imminent delivery. Studies have shown hypoglycemia in neonates whose mothers were given isoxsuprine. Mechanisms involved include drug-induced maternal hyperglycemia, fetal hyperinsulinism as a consequence of fetal hyperglycemia via direct effect to the liver, and depletion of fetal hepatic glycogen stores. [12-14] Although tocolysis in our study was not significantly associated with the development of neonatal hypoglycemia, the increased likelihood of developing neonatal hypoglycemia among mothers given isoxsuprine can be explained by this observation.

\section{LIMITATIONS AND RECOMMENDATIONS}

The results of our study show the limitations of a chart review where monitoring and intervention for the subjects cannot be controlled. The results could be more valuable if the newborns had been monitored with standardized serial monitoring of blood glucose levels up to the $24^{\text {th }}$ hour of life, before early feeding. On the other hand, all mothers should be subjected to standardized serial monitoring of blood sugar levels. These can be realized using a prospective study. Investigation on the difference between dexamethasone and betamethasone in terms of its significance to neonatal hypoglycemia can also be done to further understand the mechanisms of steroids in the development of neonatal hypoglycemia. Finally, a larger and homogenous population would result in better precision in the analysis of maternal and neonatal factors. This can be done by covering longer dates of admission for mothers and their neonates.

\section{CONCLUSION}

Antenatal corticosteroids have shown to decrease the rate of perinatal complications, but despite the benefits, it may predispose neonates to hypoglycemia requiring further intervention and prolonged nursery admission. It is important to screen and treat neonates at risk because long-term neurodevelopmental complications may ensue.

Despite these known observations, our study showed that antenatal steroids given to mothers who delivered preterm was not associated with neonatal hypoglycemia. A prospective study model, larger population size and longer study coverage should be done to strengthen the outcome of the study. 


\section{REFERENCES}

1. Beck S, Wojdyla D, Say L, Pilar Bertran A, Meraldi M, Harris Requejo J, et al. The worldwide incidence of preterm birth: a systematic review of maternal mortality and morbidity. Bull World Health Org [Internet]. 2010 Jan 1;88(1):318. Available from: http://dx.doi.org/10.2471/ BLT.08.062554

2. Kuperstock J, Sung J, Taslimi M, Byrne J, El-Sayed $Y$, Langen E. Maternal glucose response to betamethasone administration. Amer J Perinatol [Internet]. 2014 Jun 10;30(2):143-8. Available from: http://dx.doi. org/10.1055/s-0034-1376387

3. Pettit KE, Tran SH, Lee E, Caughey AB. The association of antenatal corticosteroids with neonatal hypoglycemia and hyperbilirubinemia. The Journal of Maternal-Fetal \& Neonatal Medicine [Internet]. 2013 Sep 5;27(7):683-6. Available from: http://dx.doi.org/10.3109/14767058.2013.8 32750

4. Aydin M, Deveci U, Hakan N. Neonatal hypoglycemia associated with the antenatal corticosteroids may be secondary to fetal adrenal suppression. The Journal of Maternal-Fetal \& Neonatal Medicine [Internet]. 2014 Jul 3;28(8):892-892. Available from: http://dx.doi.org/10. $3109 / 14767058.2014 .936002$

5. Harris DL, Weston PJ, Harding JE. Incidence of neonatal hypoglycemia in babies identified as at risk. The Journal of Pediatrics [Internet]. $2012 \mathrm{Nov} ; 161$ (5):787-91. Available from: http://dx.doi.org/10.1016/i.jpeds.2012.05.022

6. Voormolen DN, de Wit L, van Rijn BB, DeVries JH, Heringa $M P$, Franx $A$, et al. Neonatal hypoglycemia following dietcontrolled and insulin-treated gestational diabetes mellitus. Dia Care [Internet]. 2018 Apr 13;41 (7):1385-90. Available from: http://dx.doi.org/10.2337/dc18-0048

7. Talmadge K, Philipson L, Reusch J, Hill-Briggs F, Youssef $G$, Bertha B, et al. Standards of medical care in diabetes-2018. American Diabetes Association Officers Chair Of The Board. 2018;150.

8. Blumer I, Hadar E, Hadden DR, Jovanovi区 L, Mestman $J H$, Murad MH, et al. Diabetes and pregnancy: an endocrine society clinical practice guideline. The Journal of Clinical Endocrinology \& Metabolism [Internet]. 2013 Nov 1;98(1 1):4227-49. Available from: http://dx.doi. org/10.1210/jc.2013-2465

9. Kfouri J, D'Souza R. Antenatal corticosteroids. CMAJ [Internef]. 2017 Feb 26;189(8):E319-E319. Available from: http://dx.doi.org/10.1503/cmaj. 160392

10. Tas E, Garibaldi L, Muzumdar R. Glucose homeostasis in newborns: an endocrinology perspective. Neoreviews [Internet]. 2020 Jan;21(1):e14-29. Available from: http://dx.doi.org/10.1542/neo.21-1-e14

11. Thompson-Branch A, Havranek T. Neonatal hypoglycemia. Pediatrics in Review [Internet]. 2017 Mar
31;38(4):147-57. Available from: http://dx.doi. org/10.1542/pir.2016-0063

12. Brazy JE, Pupkin M. Effects of maternal isoxsuprine administration on preterm infants. The Journal of Pediatrics [Internet]. 1979 Mar;94(3):444-8. Available from: http:// dx.doi.org/10.1016/s0022-3476(79)80599-5

13. Epstein MF, Nicholls E, Stubblefield PG. Neonatal hypoglycemia after beta-sympathomimetic tocolytic therapy. The Journal of Pediatrics [Internet]. 1979 Mar;94(3):44953. Available from: http://dx.doi.org/10.1016/ s0022-3476(79)80600-9

14. Procianoy RS, Pinheiro CEA. Neonatal hyperinsulinism after short-term maternal beta sympathomimetic therapy. The Journal of Pediatrics [Internet]. 1982 Oct;101(4):6124. Available from: http://dx.doi.org/10.1016/ s0022-3476(82)80722-1

15. Begum S, Dey S, Fatema K. Neonatal glycemic status of infants of diabetic mothers in a tertiary care hospital. Indian J Endocr Metab [Internet]. 2018;22(5):621. Available from: http://dx.doi.org/10.4103/ijem.IJEM_689_17

16. Chan JCN, Malik V, Jia W, Kadowaki T, Yajnik CS, Yoon K-H, et al. Diabetes in Asia. JAMA [Internet]. 2009 May 27;301(20):2129. Available from: http://dx.doi. org/10.1001/jama.2009.726

17. World Health Organization. Global Report on Diabetes. Genève, Switzerland: World Health Organization; 2016.

18. Skoll A, Boutin A, Bujold E, Burrows J, Crane J, Geary M, et al. No. 364-Antenatal corticosteroid therapy for improving neonatal outcomes. Journal of Obstetrics and Gynaecology Canada [Internet]. 2018 Sep;40(9):1219-39. Available from: http://dx.doi.org/10.1016/i.jogc.2018.04.018

19. Pintaudi $B$, Fresa R, Dalfrà $M$, Dodesini $A R$, Vitacolonna $E$, Tumminia $A$, et al. The risk stratification of adverse neonatal outcomes in women with gestational diabetes (STRONG) study. Acta Diabetol [Internet]. $2018 \mathrm{Sep}$ 17;55(12):1261-73. Available from: http://dx.doi. org/10.1007/s00592-018-1208-x

(i) Open Access This article is licensed under a Creative Commons Attribution 4.0 International License, which permits use, sharing, adaptation, distribution and reproduction in any medium or format, as long as you give appropriate credit to the original author(s) and the source, provide a link to the Creative Commons license, and indicate if changes were made. The images or other third party material in this article are included in the article's Creative Commons license, unless indicated otherwise in a credit line to the material. If material is not included in the article's Creative Commons license and your intended use is not permitted by statutory regulation or exceeds the permitted use, you will need to obtain permission directly from the copyright holder. To view a copy of this license, visit http://creativecommons.org/licenses/by/4.0/. 